

\title{
Lengthening and transfer of hamstrings for a flexion deformity of the knee in children with bilateral cerebral palsy
}

\author{
TECHNIQUE AND PRELIMINARY RESULTS
}

F. Y. P. Ma,
P. Selber,
G. R. Nattrass,
A. R. Harvey,
R. Wolfe,
H. K. Graham

From The Royal Children's Hospital, Victoria, Australia

F. Y. P. Ma, MB, BS, Research Fellow in Orthopaedic Surgery P. Selber, MD, FRACS Consultant Orthopaedic Surgeon

G. R. Nattrass, MD, FRCSC, FRACS, Consultant

Orthopaedic Surgeon A. R. Harvey, BAppSc (PT), M. Physio, Research Physiotherapist Department of Orthopaedic Surgery

The Royal Children's Hospital, Flemington Road, Parkville, Victoria 3052 , Australia.

H. K. Graham, MD, FRCS (Ed), FRACS, Professor of Orthopaedic Surgery Department of Orthopaedic Surgery,

University of Melbourne and Murdoch Children's

Research Institute, Hugh

Williamson Gait Laboratory,

Flemington Road, Parkville,

Victoria 3052, Australia.

R. Wolfe, PhD, Medical Statistician

Department of Epidemiology and Preventive Medicine Monash University, Alfred Hospital, Prahran 3004, Victoria, Australia.

Correspondence should be sent to Professor H. K. Graham; e-mail: kerr.graham@rch.org.au

(C)2006 British Editorial Society of Bone and Joint Surgery

doi:10.1302/0301-620X.88B2 $16797 \$ 2.00$

$J$ Bone Joint Surg $[B r]$ 2006;88-B:248-54.

Received 31 May 2005;

Accepted after revision

25 October 2005

Between July 2000 and April 2004, 19 patients with bilateral spastic cerebral palsy who required an assistive device to walk had combined lengthening-transfer of the medial hamstrings as part of multilevel surgery. A standardised physical examination, measurement of the Functional Mobility Scale score and video or instrumented gait analysis were performed pre- and post-operatively. Static parameters (popliteal angle, flexion deformity of the knee) and sagittal knee kinematic parameters (knee flexion at initial contact, minimum knee flexion during stance, mean knee flexion during stance) were recorded. The mean length of follow-up was 25 months (14 to 45).

Statistically significant improvements in static and dynamic outcome parameters were found, corresponding to improvements in gait and functional mobility as determined by the Functional Mobility Scale. Mild hyperextension of the knee during gait developed in two patients and was controlled by adjustment of their ankle-foot orthosis. Residual flexion deformity $>10^{\circ}$ occurred in both knees of one patient and was treated by anterior distal femoral physeal stapling. Two children also showed an improvement of one level in the Gross Motor Function Classification System.

A flexion deformity of the knee and a flexed knee gait are common in children with spastic cerebral palsy and may contribute to pain in the knee and difficulty in walking. A flexion deformity may result from spastic muscle imbalance around the knee, but limited walking ability and time spent sitting with the knees flexed also contribute. ${ }^{1}$

The incidence of a flexion deformity of the knee increases with the severity of neurological involvement and is best described in children with cerebral palsy by the Gross Motor Function Classification System (GMFCS) based on the description of self-initiated movement, the ability to sit and walk, and the need for assistive devices and mobility aids. ${ }^{2}$ The GMFCS is a five-level, ordinal grading system used to describe gross motor function in children with cerebral palsy. It has been shown to be valid, reliable and stable over time. ${ }^{2}$

The incidence and severity of a flexion deformity of the knee and flexed knee postures increases from GMFCS level I to level V. The natural history of a flexion deformity varies in each GMFCS group and it would seem logical that operations should be based on the GMFCS level and the presumed natural history.

After the introduction of hamstring lengthening, transfer of the hamstrings to the distal femur together with medial and lateral patellar retinacular release was first suggested by Eggers $^{3}$ and practised by a number of surgeons for a relatively short period of time., ${ }^{4,5}$ The enthusiasm for transferring all of the hamstring tendons to the femur was short-lived. The improvements of the flexion deformity and extension of the knee in stance were compromised by loss of active knee flexion and the development of recurvatum in a significant number of patients. Modifications of the technique were quickly introduced in the 1950s and $1960 \mathrm{s.}^{4-7}$

At our tertiary level children's hospital, surgical treatment is based on the child's GMFCS level, which we believe provides both a guide to the natural history and a realistic view of long-term gross motor function. ${ }^{8}$ Children at GMFCS level I have good function and, although some have increased knee flexion during gait, they do not develop a flexion deformity and usually require management of spasticity rather than surgery for contractures. Children at GMFCS level II may require management of spasticity, but if deformity becomes fixed, conservative lengthening of the medial hamstrings is performed as part of multilevel surgery. Children with flexion deformities of the knee at GMFCS levels III and IV are man- 
Table I. Clinical details and surgical treatment in the 19 patients

\begin{tabular}{|c|c|c|c|c|c|c|c|c|c|c|c|}
\hline \multirow[b]{2}{*}{ Case } & \multirow[b]{2}{*}{ Gender } & \multirow[b]{2}{*}{ GMFCS $^{*}$} & \multirow{2}{*}{$\begin{array}{l}\text { Age at } \\
\text { surgery }\end{array}$} & \multirow{2}{*}{$\begin{array}{l}\text { Age at } \\
\text { follow-up }\end{array}$} & \multirow{2}{*}{$\begin{array}{l}\text { Length of follow-up } \\
\text { (mths) }\end{array}$} & \multirow{2}{*}{$\begin{array}{l}\text { Sagittal gait } \\
\text { pattern }^{\dagger}\end{array}$} & \multirow{2}{*}{$\begin{array}{l}\text { Gait analysis } \\
\text { type }^{\ddagger}\end{array}$} & \multicolumn{4}{|c|}{ Surgery performed ${ }^{\S}$} \\
\hline & & & & & & & & MHLT & LHS & РОтВ & Calf \\
\hline 1 & $\mathrm{~F}$ & IV & $5 y 2 m$ & $8 y 11 \mathrm{~m}$ & 45 & Jump & Video & 1 & 0 & 1 & GR \\
\hline 2 & $M$ & IV & $6 y 4 m$ & $9 y 9 m$ & 41 & $\mathrm{AE}$ & Video & 1 & 1 & 1 & $\mathrm{~B}^{\mathbb{I}}$ \\
\hline 3 & $\mathrm{~F}$ & III & $5 y 8 m$ & $8 y 11 m$ & 39 & Jump & 3DGA & 1 & 0 & 1 & GR \\
\hline 4 & $M$ & IV & $6 y 1 \mathrm{~m}$ & $8 y 4 m$ & 27 & $\mathrm{AE}$ & Video & 1 & 1 & 1 & B \\
\hline 5 & $M$ & IV & $12 y 7 m$ & $14 y 6 m$ & 23 & $\mathrm{AE}$ & Video & 1 & 1 & 0 & $B$ \\
\hline 6 & $M$ & III & 10 y $9 m$ & $12 \mathrm{y} 11 \mathrm{~m}$ & 26 & Jump & 3DGA & 1 & 0 & 1 & GR \\
\hline 7 & $\mathrm{~F}$ & III & $7 y 4 m$ & $9 y 9 m$ & 29 & Crouch & 3DGA & 1 & 0 & 1 & 0 \\
\hline 8 & $\mathrm{~F}$ & IV & $9 y 3 m$ & $11 y 6 m$ & 27 & $\mathrm{AE}$ & Video & 1 & 1 & 1 & B \\
\hline 9 & $M$ & III & $13 y$ & $15 y 3 m$ & 27 & Crouch & 3DGA & 1 & 1 & 0 & 0 \\
\hline 10 & $M$ & IV & $11 \mathrm{y} 6 \mathrm{~m}$ & $13 y 4 m$ & 22 & $\mathrm{AE}$ & Video & 1 & 0 & 1 & GR \\
\hline 11 & $\mathrm{~F}$ & III & $13 y 4 m$ & $15 y 1 m$ & 21 & Crouch & 3DGA & 1 & 0 & 1 & GR \\
\hline 12 & $\mathrm{M}$ & III & $14 y 2 m$ & $16 y$ & 22 & Jump & 3DGA & 1 & 0 & 1 & 0 \\
\hline 13 & $M$ & III & $6 y 9 m$ & $8 y 7 m$ & 22 & Jump & 3DGA & 1 & 0 & 0 & B \\
\hline 14 & $M$ & IV & $8 y 7 m$ & $10 y 4 m$ & 21 & Crouch & Video & 1 & 1 & 1 & B \\
\hline 15 & $\mathrm{~F}$ & IV & $7 y 3 m$ & $8 y 9 m$ & 18 & $\mathrm{AE}$ & Video & 1 & 0 & 1 & $B$ \\
\hline 16 & $\mathrm{~F}$ & III & $6 y 5 m$ & $7 y 11 \mathrm{~m}$ & 18 & Jump & 3DGA & 1 & 0 & 1 & GR \\
\hline 17 & $\mathrm{~F}$ & IV & $9 y 6 m$ & $10 \mathrm{y} 10 \mathrm{~m}$ & 16 & Jump & Video & 1 & 1 & 1 & GR \\
\hline 18 & $M$ & III & $9 y 11 \mathrm{~m}$ & $11 y 3 m$ & 16 & $\mathrm{AE}$ & 3DGA & 1 & 0 & 1 & B \\
\hline 19 & $\mathrm{~F}$ & III & $8 y 11 m$ & $9 y 3 m$ & 14 & Crouch & 3DGA & 1 & 0 & 1 & 0 \\
\hline
\end{tabular}

* GMFCS, Gross Motor Function Classification System

$\dagger \mathrm{AE}$, apparent equinus

₹ 3DGA, 3-dimensional gait analysis; video, video analysis of gait

$\S \mathrm{MHLT}$, medial hamstrings lengthening and semitendinosus transfer; LHS, lateral hamstrings surgery (fractional lengthening of biceps femoris); POTB, psoas tendon lengthening over the brim; GR, gastrocnemius recession (Strayer type)

If $B$, botulinum toxin

aged by transfer of semitendinosus to the adductor tubercle and fractional lengthening of semimembranosus, gracilis and biceps femoris. Children at GMFCS level V can be managed by simple tenotomy for a flexion contracture of the knee, when indicated.

The GMFCS is reported to be stable over time and not to be responsive to change after intervention. ${ }^{2}$ In order to determine the outcome of surgical intervention, a more responsive scale is required. The Functional Mobility Scale ${ }^{9}$ is a measure of the assistance required by children with cerebral palsy to move over three distinct distances, five, 50 and 500 metres, representing mobility in the home, school and the community. This is a six-level ordinal scale, with level 6 indicating that the child can walk unassisted on all surfaces and level 1 that they are wheelchair-dependent. This scale has been shown to be valid, reliable and sensitive to change after multilevel surgery. ${ }^{9}$ It is useful in monitoring progress after surgery and has been shown to be sensitive in detecting both the initial deterioration and the ultimate improvement in mobility after multilevel orthopaedic surgery to improve gait in children with cerebral palsy. ${ }^{9}$

We report the results of our first series of children with bilateral spastic cerebral palsy and GMFCS levels III and IV who received the combined procedure of semitendinosus transfer and hamstring lengthening for a flexion deformity of the knee and a flexed knee gait.

\section{Patients and Methods}

The indications for combined hamstring lengthening and transfer were: 1) bilateral spastic cerebral palsy (spastic diplegia and quadriplegia); 2) a flexion deformity of the knee of $\geq 15^{\circ}$ in combination with a flexed knee posture in standing and walking; 3) GMFCS level III or IV, indicating that walking and standing were only possible with the aid of an assistive device; and 4) pre- and post-operative assessment by an experienced physiotherapist and recording of gross motor function by the GMFCS $^{2}$ and Functional Mobility Scale. ${ }^{9}$

For the purposes of this preliminary study, we included patients who had hamstring lengthening-transfer in the context of multilevel soft-tissue surgery. We excluded children who had bony surgery, such as femoral osteotomy, tibial osteotomy and foot-stabilisation procedures, to minimise the confounders on recovery and function.

Between July 2000 and April 2004, 19 children and adolescents (38 knees) with bilateral spastic cerebral palsy and a fixed flexion deformity of the knee had combined lengthening-transfer of the medial hamstrings, in the context of multilevel soft-tissue surgery to improve gait and function. Ten were at GMFCS level III and nine at level IV. The mean age at surgery was nine years (five to 14) and at follow-up 11 years (eight to 16). All underwent semitendinosus transfer to the adductor magnus tendon and fractional lengthening of gracilis and semimembranosus in combination with other proximal and distal procedures as part of their multilevel surgery. Other procedures performed included fractional lengthening of biceps (seven patients), ${ }^{10}$ intramuscular lengthening of psoas over the brim of the pelvis for a flexion deformity of the hip $(16)^{11}$ and management of equinus deformity of the ankle with either botulinum toxin $(8)^{11}$ or by a Strayer-type recession of gastrocnemius (7). ${ }^{12}$ Table I gives the clinical details and surgical treatment. 


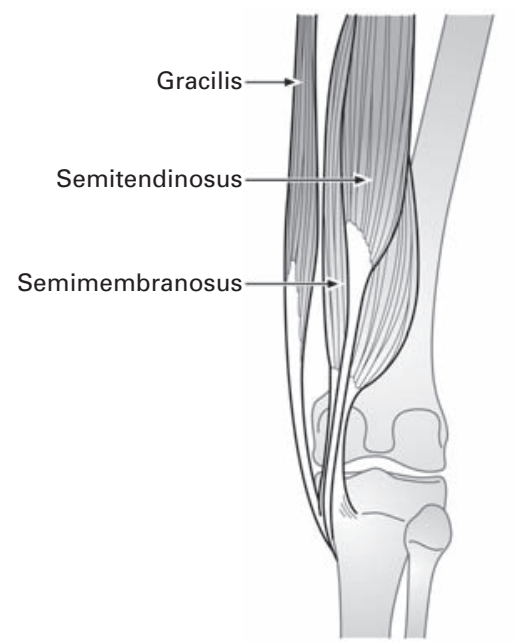

Fig. 1a

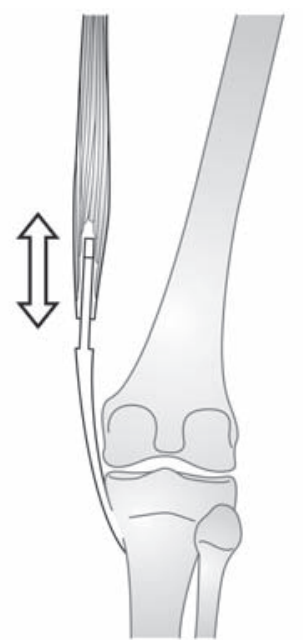

Fig. 1b

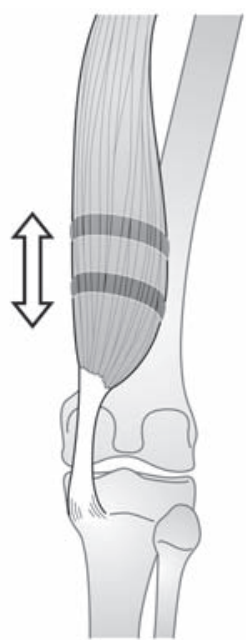

Fig. 1c
Diagrams showing a) the anatomy of the three medial hamstring muscle-tendon units, b) intramuscular lengthening of gracilis, and c) fractional lengthening of semimembranosus.

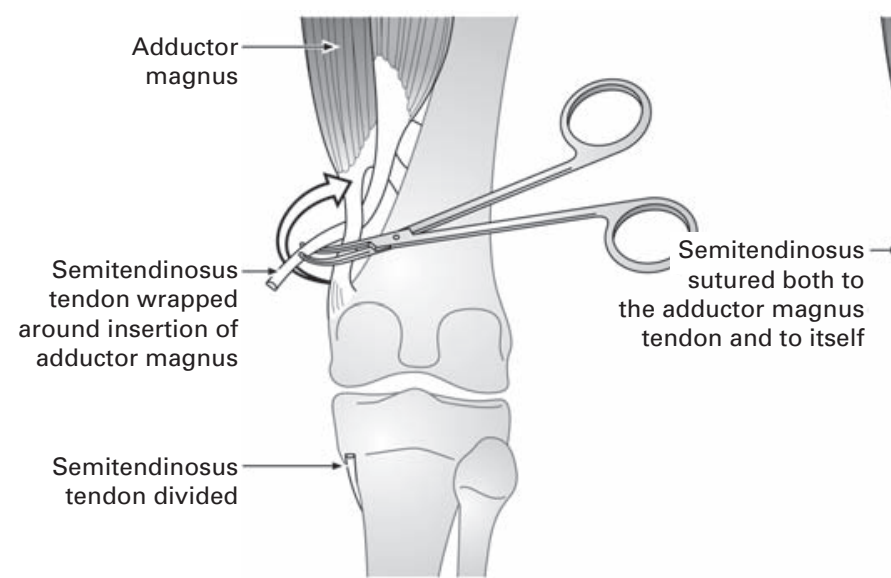

Fig. 2a

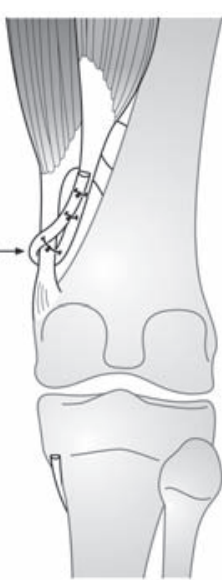

Fig. $2 b$
Diagram showing transfer of semitendinosus to the tendon of adductor magnus.
Each child was evaluated by the taking of a comprehensive history, physical examination, videotaping of standing and walking, and when feasible, instrumented gait analysis. Static joint examination was performed using a standardised protocol, which has been previously described and which has acceptable reliability. ${ }^{13}$ Emphasis was placed on the measurement of the popliteal angle and flexion deformity of the knee. Some children at GMFCS level III were capable of having a three-dimensional instrumented gait analysis including kinematic capture, but not the capture of kinetics. Children at GMFCS level IV in our centre have a two-dimensional video recording of gait, but are not capable of three-dimensional instrumented gait analysis. This was performed using reflective markers placed on the lower limbs according to the standard Vicon Clinical Manager protocol (Vicon; Oxford Metrics Ltd, Oxford, UK). Six cameras, set at $50 \mathrm{~Hz}$, collected three-dimensional move- ment data (Vicon 370 System; Oxford Metrics Ltd) for analysis using Vicon Clinical Management (Oxford Metrics Ltd). Children were asked to walk at a self-selected walking speed and multiple trials were captured, from which a representative trial was identified for subsequent analysis. Sagittal knee kinematic parameters for analysis included knee flexion at initial contact, maximum knee extension during stance and mean knee extension during the stance phase. Sagittal gait patterns were classified as jump gait, apparent equinus, or crouch as previously described by Rodda et al. ${ }^{14}$ A physiotherapist (ARH) recorded the Functional Mobility Scale before surgery and at the most recent follow-up.

Operations technique. With the patient in the prone position, the medial hamstrings (Fig. 1a) are approached through a midline popliteal skin incision measuring 3 to 6 $\mathrm{cm}$ in length. Semitendinosus is mobilised close to its tibial 
Table II. Mean (SD; ${ }^{\circ}$ ) static and dynamic knee parameters and Functional Mobility Scale (FMS) scores before and after combined hamstrings lengthening- transfer at a mean of 2.1 years after surgery

\begin{tabular}{|c|c|c|c|c|}
\hline & Pre-operative & Post-operative & Change & $\begin{array}{l}p \text { value for } \\
\text { change }\end{array}$ \\
\hline \multicolumn{5}{|l|}{ Static parameters } \\
\hline \multicolumn{5}{|l|}{ Popliteal angle } \\
\hline Right knee & $69.9(8.9)$ & $42.3(9.5)$ & $-27.6(8.7)$ & $<0.0001$ \\
\hline Left knee & $70.2(9.5)$ & $42.8(9.5)$ & $-27.3(8.5)$ & $<0.0001$ \\
\hline \multicolumn{5}{|l|}{ Flexion deformity } \\
\hline Right knee & $17.0(4.3)$ & $2.7(3.9)$ & $-14.3(2.6)$ & $<0.0001$ \\
\hline Left knee & $18.2(3.6)$ & $3.5(3.6)$ & $-14.6(3.1)$ & $<0.0001$ \\
\hline \multicolumn{5}{|l|}{ Dynamic parameters } \\
\hline Knee flexion at initial contact & $39 \quad(8)$ & $22 \quad(7)$ & $-17 \quad(7)$ & $<0.001$ \\
\hline Minimum knee flexion (stance) & $26 \quad(8)$ & $8 \quad(9)$ & $-18 \quad(8)$ & $<0.001$ \\
\hline Mean knee flexion (stance) & $34 \quad(8)$ & $16 \quad(9)$ & $-18 \quad(8)$ & $<0.001$ \\
\hline \multicolumn{5}{|l|}{ Median FMS scores } \\
\hline 5 metres & 2 & 3 & 1 & 0.005 \\
\hline 50 metres & 2 & 3 & 1 & 0.002 \\
\hline 500 metres & 2 & 2 & 0 & 0.08 \\
\hline
\end{tabular}

insertion, divided and drawn up into the proximal part of the incision. Gracilis is lengthened by intramuscular tenotomy (Fig. 1b); the semimembranosus, and when indicated, biceps femoris are lengthened by a fractional technique involving one or two oblique incisions in the fascia (Fig. 1c). Biceps is lengthened only when the flexion deformity of the knee is $10^{\circ}$ or more, after lengthening of the medial hamstrings. The tendon of adductor magnus is palpated and followed to its insertion at the adductor tubercle. Retractors are inserted and the adductor magnus tendon viewed by gently cleaning the overlying fat from its surface. A right-angle clamp is passed from lateral to medial underneath the adductor magnus tendon and grasps semitendinosus (Fig. 2). This is pulled through from medial to lateral and then sutured to itself and to the adductor magnus tendon with No 1 Ethibond (Ethicon Inc., Somerville, New Jersey) under slight tension (Fig. 2). The wound is closed in layers with careful closure of the deep fascia to prevent the lengthened hamstring tendons adhering to skin.

Post-operatively, the patient is immobilised in a removable knee splint or temporary back slab, depending on what additional surgery has been undertaken. ${ }^{11}$ Patients are managed by epidural infusion intra- and post-operatively. Sitting is restricted to $70^{\circ}$ for three weeks to minimise tension on the semitendinosus transfer. Weight-bearing is begun as tolerated, unless other surgery dictates otherwise. All patients are fully weight-bearing by three weeks after operation.

Most children with flexion deformities of the knee greater than $15^{\circ}$ will have an overt or occult flexion deformity of the hip which should be treated at the same operative session. ${ }^{11}$ Some will also have a contracture of gastrocnemius which may require recession. ${ }^{11}$

Statistical analysis. The popliteal angle, fixed-flexion deformity of the knee and knee kinematic parameters after surgery were compared with the pre-operative values using the paired $t$-test. For the Functional Mobility Scale, post-operative were compared with pre-operative values using the
Wilcoxon signed-rank test. A p value of $<0.05$ was considered to be significant and all analyses were performed in Stata statistical software, Release 8.0 (Stata Corporation, College Station, Texas).

\section{Results}

Static parameters (Table II). Pre-operatively, the mean popliteal angle at the right and left knees was $69.9^{\circ}$ and $70.2^{\circ}$, respectively, which improved after operation to $42.3^{\circ}$ and $42.8^{\circ}$, respectively. The mean differences in the pre- and post-operative popliteal angle of $27.6^{\circ}$ on the right and $27.2^{\circ}$ on the left were statistically significant $(\mathrm{p}<0.0001)$. The mean fixed- flexion deformity on the right was $17^{\circ}$ and $18.2^{\circ}$ on the left, improving to $2.7^{\circ}$ and $3.5^{\circ}$, respectively ( $\mathrm{p}$ $<0.0001$ ).

Dynamic parameters (Table II). The mean knee flexion at initial contact improved from a pre-operative value of $39^{\circ}$ to $22^{\circ}$ post-operatively with a statistically significant change of $17^{\circ}(p<0.001)$. The mean minimum knee flexion during the stance phase improved from $26^{\circ}$ pre-operatively to $8^{\circ}$ post-operatively $(\mathrm{p}<0.001)$. The mean knee flexion during the stance phase improved from $34^{\circ}$ pre-operatively to $16^{\circ}$ post-operatively $(\mathrm{p}<0.001)$. Figure 3 shows the mean pre- and post-operative sagittal knee kinematics of the ten patients at GMFCS level III who were capable of a three-dimensional gait analysis. Significant improvements were found in dynamic knee function and no deterioration was noted in pelvic tilt.

Functional parameters (Table II). The median Functional Mobility Scale scores for five, 50 and 500 metres were 2, 2 and 2, respectively pre-operatively, improving to 3, 3 and 2, respectively after operation. These changes in the Functional Mobility Scale were statistically-significant for the 5 and 50 metre scores $(\mathrm{p}=0.005$ and $\mathrm{p}=0.002$, respectively); but not the 500 metre score $(\mathrm{p}=0.08)$.

Complications. There were no infections, nerve palsies or vascular complications. However, three knees in two patients developed mild hyperextension during gait. These 
were managed by solid ankle-foot orthoses and have had no further progression of the deformity to date. One patient (case 5) had residual bilateral flexion deformities of the knee greater than $10^{\circ}$ at the final follow-up. This boy, aged 14 years 6 months, was treated by anterior distal femoral physeal stapling.

\section{Discussion}

A flexed knee gait is very common in children and adolescents with bilateral spastic cerebral palsy and is part of the pattern of jump knee, apparent equinus and crouch gait as described by Rodda et al. ${ }^{14}$ Given the variety of gait patterns and variations in the severity of the flexion deformity of the knee, a range of procedures may be required to manage flexed knee gait in such children. At our institution children with flexed knee gait and flexion deformities of the knee of less than $10^{\circ}$ to $15^{\circ}$ are managed by conservative hamstrings lengthening as part of a single-event, multilevel surgery. Children with flexed knee gait and a flexion deformity of the knee between $15^{\circ}$ and $25^{\circ}$ undergo combined medial hamstrings lengthening and transfer of semitendinosus to the adductor tubercle. Flexion deformities greater than $25^{\circ}$ may require bony procedures such as anterior distal femoral physeal stapling ${ }^{15}$ or distal femoral extension osteotomy. ${ }^{16,17}$

The development of instrumented gait analysis, supplemented by musculoskeletal modelling, has suggested that hamstring shortening is not as common an issue as was once thought, when clinicians were guided purely by clinical examination. ${ }^{18-20}$ Some children with flexed knee gait have shortened hamstrings, but others have hamstrings of normal or even excessive length. ${ }^{18-20}$ The fact remains, however, that most children, especially those with more severe motor involvement, are prone to develop flexion contractures of the knee, resulting in severe knee flexion during attempts to stand and walk, which greatly limits function. ${ }^{1,21}$ Recurrent knee flexion postures are very common in these more severely-involved children. It is likely that this provided the impetus for the development of the hamstrings transfer procedures described by Eggers ${ }^{3}$ and others. ${ }^{4,5}$

Existing studies have a lack of data regarding functional outcomes and there are no studies reporting validated mobility scales or instrumented gait analysis, apart from the recent study by Metaxiotis, Wolf and Doederlein. ${ }^{22}$ They reported the outcome of transferring semitendinosus to the medial tendinous stump of gastrocnemius, combined with additional soft tissue and bony procedures. ${ }^{22}$ The improvements in dynamic knee function in their study were very similar to the present study and as in this study were achieved without an increase in anterior pelvic tilt. ${ }^{22}$

We selected a conservative approach to hamstring transfer surgery, by lengthening of gracilis and semimembranosus and transfer of only semitendinosus. Its use was restricted to those children who had established flexion deformities of the knee and whose GMFCS level suggested

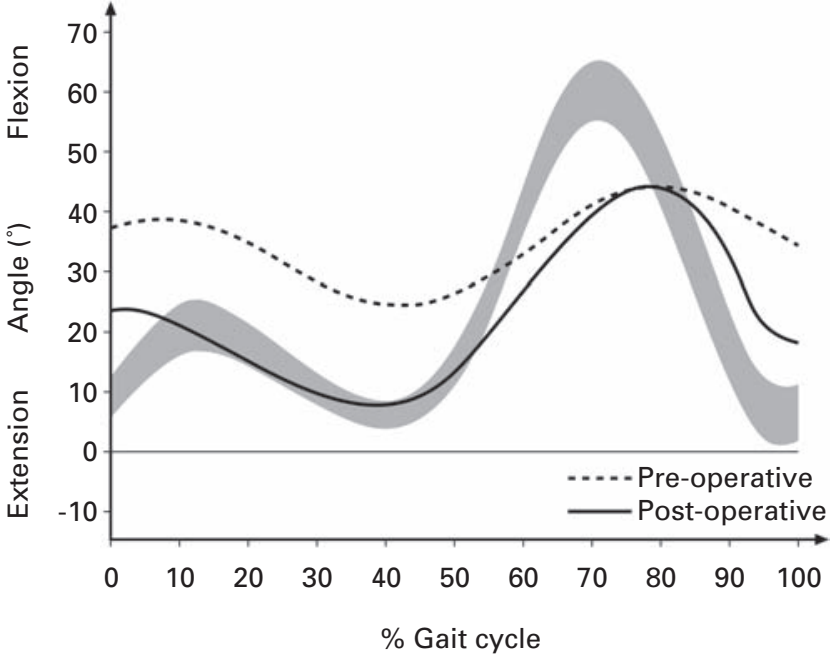

Fig. 3

Graph showing sagittal knee kinematics before and after combined medial hamstring lengthening-transfer. The grey band is the gait laboratory normal range. The dotted line is the mean sagittal knee kinematic of the ten patients who were at GMFCS level III, before surgery. The solid line is the mean sagittal knee kinematic for these ten patients at 12 months after surgery.

that they would be prone to recurrent flexion contractures of the knee. Transferring semitendinosus removes it as a knee flexor but retains it as a hip extensor. The latter function is very important in minimising the increase in anterior pelvic tilt which is often observed when all the hamstrings are lengthened. Increased anterior pelvic tilt can lead to an increase in lumbar lordosis, low back pain and spinal instability. ${ }^{11,17,21}$ The overall effect is to weaken the knee flexors sufficiently to allow knee extension during gait but to preserve adequate strength for active hip extension and knee flexion during gait. ${ }^{22}$

We have found the procedure to be simple to perform. It has been effective in the short term in the correction of a flexion deformity of the knee in most children and has resulted in improvement in standing and walking as assessed by the Functional Mobility Scale.

No knees developed extension deformities, although three in two children showed mild hyperextension on instrumented gait analysis. This was easily controlled by adjustment of the ankle-foot orthosis by a plantar-flexion stop, to redirect the ground reaction force closer to the knee. Residual flexion deformities of the knee were corrected in one adolescent by anterior distal femoral physeal stapling. ${ }^{15}$

Statistically-significant improvements in the popliteal angle, flexion deformity and dynamic knee function parameters were associated with improved mobility. Children required less support to walk shorter distances ( 5 and 50 metres), but not for community distances ( 500 metres). The improvements in the Functional Mobility Scale at 5 and 50 metres, corresponded to improvement in standing for transfers and mobility in the home and at school. 


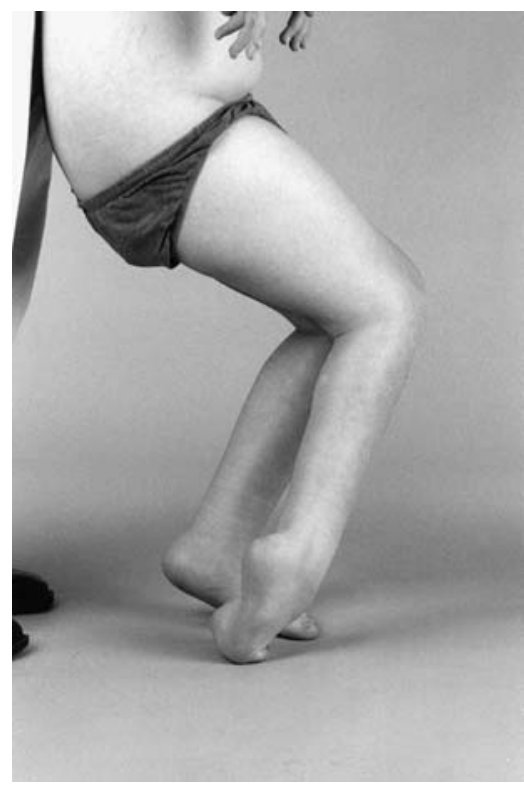

Fig. $4 a$

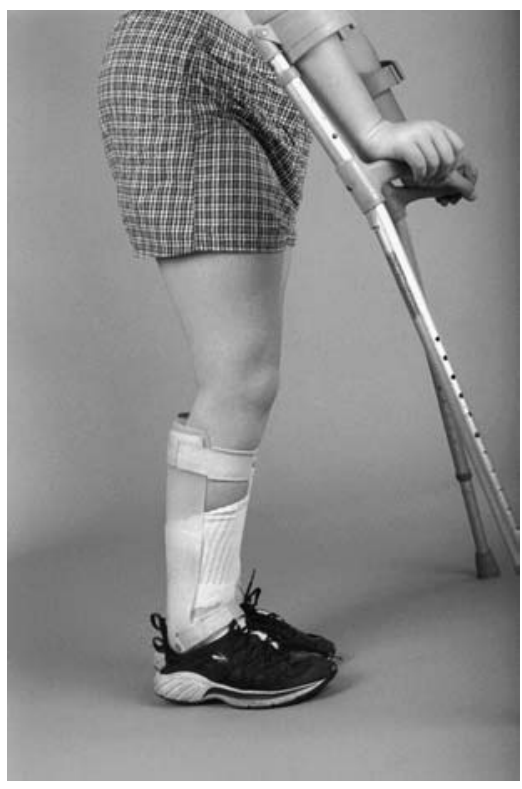

Fig. $4 b$
Case 5. Photographs showing a) the patient pre-operatively standing with maximal support; GMFCS IV, Functional Mobility Scale 2, 1, 1 and b) at 23 months after operation, standing with arm crutches; GMFCS III, Functional Mobility Scale 3, 3, 1.
Figure 3 summarises the mean sagittal kinematics of the ten GMFCS level-III patients who were capable of an instrumented gait analysis. The pre- and post-operative values were compared with those of able-bodied children. Knee flexion at initial contact improved after surgery, but was still greater than normal. Knee extension approximated to normal values during the loading response and the mid and terminal stance phase. Peak knee flexion was reduced in the swing phase, but the range of movement of the knee improved significantly. These kinematic improvements reflected the clinical improvements in mobility and hence the Functional Mobility Scale.

Two patients have improved by one GMFCS level. The GMFCS is believed to be stable over time, ${ }^{2}$ as opposed to the Functional Mobility Scale which is expected to vary with natural history or surgical intervention. One patient (case 5) as depicted in Figure 4 is a good example. Preoperatively, he was at GMFCS level IV and Function Mobility Scale 2, 1, 1. Post-operatively, he improved to GMFCS level III and Functional Mobility Scale 3, 3, 1.

The finding that two patients in our series improved by one level on the GMFCS scale is of functional significance for these two patients. It is also of considerable importance in terms of our theoretical framework for understanding gross motor function in children with cerebral palsy. Children may not necessarily be condemned to remain within a level of gross motor function dictated by their cerebral lesion and neurological involvement. Gross motor function may be adversely affected by secondary musculoskeletal pathology. Correction of fixed deformities in some children can result in a significant improvement in gross motor function. The relationship of the GMFCS level to musculoskeletal deformity and its correction deserves further study.

\section{Supplementary Material}

节 A table describing the levels of the Gross Motor Function Classification System and a figure showing the ratings of the Functional Mobility Scale are available with the electronic version of the article on our website at www.jbjs.org.uk

Professor H. Kerr Graham was supported in part by a National Health and Medical Research Council of Australia, Clinical Centre of Research Excellence grant. No benefits in any form have been received or will be received from a commercial party related directly or indirectly to the subject of this article.

\section{References}

1. Graham HK. Mechanisms of deformity. In: Scrutton D, Damiano D, Mayston M, eds. Clinics in developmental medicine No 161: management of the motor disorders of children with cerebral palsy, Second ed. London: MacKeith Press, 2004:105-29.

2. Palisano R, Rosenbaum P, Walter S, et al. Development and reliability of a system to classify gross motor function in children with cerebral palsy. Dev Med Child Neurol 1997;39:214-23.

3. Eggers GW. Transplantation of hamstring tendons to femoral condyles in order to improve hip extension and to decrease knee flexion in cerebral spastic paralysis. J Bone Joint Surg [Am] 1952;34-A:827-30.

4. Keats S, Kambin P. An evaluation of surgery for the correction of knee flexion contracture in children with cerebral spastic paralysis. J Bone Joint Surg [Am] 1962; 44-A:1146-54

5. Pollock GA. Surgical treatment of cerebral palsy. J Bone Joint Surg [Br] 1962;44-B: 68-81.

6. Eggers GW, Evans EB. Surgery in cerebral palsy. J Bone Joint Surg [Am] 1963 45-A:1275-305.

7. Evans EB, Julian JD. Modifications of the hamstring transfer. Dev Med Child Neurol 1966;8-5:539-51.

8. Graham HK. Classifying cerebral palsy. J Pediatr Orthop 2005;25:127-8.

9. Graham HK, Harvey A, Rodda J, Nattrass GR, Pirpiris M. The functional mobility scale (FMS). J Pediatr Orthop 2004;24:514-20.

10. Herring JAL. Tachdjian's pediatric orthopaedics. Third ed. Philadelphia: W.B. Saunders Co., 2002:1159-73.

11. Bache CE, Selbar P, Graham HK. The management of spastic diplegia. Curr Orthop 2003; 17:88-104.

12. Strayer LM Jr. Recession of the gastrocnemius: an operation to relieve spastic contracture of the calf muscles. J Bone Joint Surg [Am] 1950;32-A:671-6. 
13. Keenan WN, Rodda J, Wolfe R, et al. The static examination of children and young adults with cerebral palsy in the gait analysis laboratory: technique and observer agreement. J Pediatr Orthop 2004;13:1-8.

14. Rodda JM, Graham HK, Carson L, Galea MP, Wolfe R. Sagittal gait patterns in spastic diplegia. J Bone Joint Surg [Br] 2004;86-B:251-8.

15. Kramer A, Stevens PM. Anterior femoral stapling. J Pediatr Orthop 2001;21:804-7.

16. Ferraretto I, Machado PO, Filho EL, Selber P. Preliminary results of patellar tendon shortening as a salvage procedure for crouch gait in cerebral palsy [abstract]. Paediatric Orthopaedic Society North America 2000.

17. Novacheck TF. Diplegia and quadriplegia: pathology and treatment. In: Gage JR, ed. Clinics in developmental medicine No 164-165: the treatment of gait problems in cerebral palsy. London: MacKeith Press, 2004:345-81.
18. Hoffinger SA, Rab GT, Abou-Ghaida H. Hamstrings in cerebral palsy crouch gait. J Pediatr Orthop 1993;13:722-6.

19. Delp SL, Arnold AS, Speers RA, Moore CA. Hamstrings and psoas lengths during normal and crouch gait: implications for muscle-tendon surgery. J Orthop Res 1996;14:144-51.

20. Schutte LM, Hayden SW, Gage JR. Lengths of hamstrings and psoas muscles during crouch gait: effects of femoral anteversion. J Orthop Res 1997;15:615-21.

21. Miller F, Dabney KW, Rang M. Complications in cerebral palsy. In: Epps CHJB, Bowen JR, eds. Complications in pediatric orthopaedic surgery. Philadelphia: J.B. Lippincott Co., 1995:477-544.

22. Metaxiotis D, Wolf S, Doederlein L. Conversion of biarticular to monoarticular muscles as a component of multilevel surgery in spastic diplegia. J Bone Joint Surg [Br] 2004;86-1:102-9. 